\title{
A multi-method approach to studying activity setting participation: Integrating standardized questionnaires, qualitative methods, and physiological measures
}

Citation:

Gibson, BE ${ }^{1,2}$, G King ${ }^{2}$, A Kushki ${ }^{2}$, B Mistry ${ }^{2}$, L Thompson ${ }^{2}$, G Teachman ${ }^{3}$, B Batorowicz ${ }^{4}$, and M McMain$\mathrm{Klein}^{3}$. "A multi-method approach to studying activity setting participation: integrating standardized questionnaires, qualitative methods and physiological measures."Disability \& Rehabilitation 2014, Vol. 36, No. 19, Pages 1652-1660

Address for correspondence:

Barbara Gibson

University of Toronto

160-500 University Avenue, Toronto, ON M5G 1V7

E-mail: barbara.gibson@utoronto.ca

\begin{abstract}
Purpose. This study investigated the feasibility of integrating three diverse methods for studying disabled youth's experiences of activity settings: standardized questionnaires, qualitative methods, and physiological measures. The article describes a case study of data collection in a real-life setting to outline the opportunities, challenges, and lessons learned for future research.

Methods. The methods included (a) two newly-developed quantitative measures of qualities of home and community activity settings (MEQAS) and youth experiences (SEAS); (b) youthfriendly qualitative methods, including: photo-elicitation, observations, electronic interviews, and face-to-face interviews; and (c) an innovative system to collect physiological data (the HEART system) that provided insight into the experiences of youth beyond other methods. $\underline{\text { Results. }}$. The study demonstrated that these diverse methods measures can be practically combined to study activity setting participation experiences. The measures provided different types of data that informed one other and allowed a rich interpretation and deep understanding of the participant's experiences. We discuss practical lessons concerning the joint use of the three methods, lessons specific to each method, and lessons concerning next steps for integrating the data.

Conclusions. Combined methodologies hold great promise for investigations of the participation experiences of disabled youth in future research.
\end{abstract}




\section{Introduction}

In this paper we discuss the practical aspects of integrating three diverse methods for studying disabled youth's [1] experiences of activity settings: standardized questionnaires, qualitative methods, and physiological measures. We do this through the presentation of a case study drawn from a feasibility study that aimed to integrate, field test, and further develop the methods. The feasibility study was part of a project funded by a Canadian Institutes of Health Research Emerging Team Grant. The team consists of an interdisciplinary group of child health researchers from social psychology, biomedical engineering, occupational therapy, physiotherapy, geography and bioethics. The project addressed the activity setting experiences of two groups of 'hard to study' disabled youth, those with complex continuing care needs, and those who communicate using augmentative and alternative communication (AAC). These two groups of youth are frequently excluded from research because of the complexity of their care needs and or communication challenges; as such, little is known about how they experience and evaluate their everyday activity settings (i.e., places in which they 'do things'). We do not know for example, how some activity settings might better facilitate opportunities to experience meaningful interactions, engage in challenging tasks, form social bonds or friendships, or experience a sense of control or choice. To understand youth's perspectives rather than relying on parents, as is frequently the case with these groups [2-4], we aimed to develop youth-focused methods. This article describes a case study of data collection in a reallife setting to outline the opportunities, challenges, and lessons learned for future research.

The notion of an 'activity setting' was a critical concept for our investigations [5]. Activity settings refer to contextualized settings that situate child and youth activities and experiences. Activity settings provide a bridge between environmental qualities and individuals' 
experiences of participation [6], as they represent a unit of analysis that encompasses both subjective experiences and objective perception of environmental features $[7,8]$.

The team's goal was to develop an innovative toolbox of research techniques and instruments that could be used together to assess qualities of home and community activity settings, and youths' experiences of these settings. In Phase One of the project we developed the three types of methods and measures [9]: standardized measures of experiences of activity settings and environmental qualities of activity settings [10, 11], qualitative methods, and physiological measures [12]. Here we describe the practicalities of integrating these methods and measures in the field during activity setting participation, and the lessons learned for future research.

A note about terminology: although the UN Convention on the Rights of Persons with Disabilities uses the term 'persons with disabilities', we use the term 'disabled youth' to be consistent with current usage in disability studies. This usage emphasizes that individuals are disabled by physical and social barriers in the environment, as opposed to 'with disabilities' which suggests persons are disabled solely by their bodily impairments [1].

\section{Feasibility Study}

The practicalities of integrating the methods were explored in a feasibility study with two participants who each participated in two activity settings. For purposes of illustration, we describe one participant, Hannah, and one of her activities: 'shopping at the sports store'. Hannah was a 23 year-old college student with cerebral palsy who mobilized with a walker at home and power wheelchair in the community. She lived at home with her family and did not have any communication impairments. The other participant (not discussed here) was an 18 
year old AAC user. The study was approved by the Research Ethics Board of the rehabilitation centre where the study was conducted.

\section{Methods and Measures}

Below we describe each of the methods and measures used in the feasibility study. The different measures captured complementary information at different data collection points: Standardized questionnaires captured objective and subjective assessments immediately post activity, qualitative methods captured subjective perspectives during and post activity, and physiological methods captured objective measures of physiological engagement during an activity.

\section{Standardized Questionnaires}

Measure of Environmental Qualities of Activity Settings (MEQAS)

There is a widespread assumption that environmental qualities have specific effects on participation experiences, but little has been demonstrated empirically due to challenges in conceptualizing and measuring environments and participation [13]. Accordingly, we set out to develop a reliable and valid observer-rated measure of environmental qualities. Environmental qualities refer to the external features of activity settings, including their aesthetic, physical, and social characteristics and the opportunities they provide for growth and development [1416].

The MEQAS [11] provides a comprehensive, global assessment of structural and process qualities of youth activity settings, including aesthetic, physical, social, and opportunity-related qualities. These qualities are consistently referred to in the literature as important aspects of 
participatory, welcoming, and supportive environments [17]. The MEQAS provides an easily completed snapshot of a variety of important features, rather than a physical audit or detailed observational assessment of a small set of specific interactions or behaviors. The focus is on observable environmental qualities easily inferred based on short-term observation. The MEQAS was not designed to provide a tailored observation regarding the 'environmental fit' for a particular youth, but rather to provide an objective rating of generic environmental qualities.

The MEQAS was developed with input from an interdisciplinary group of content experts. It's factor structure and inter-rater and internal consistency reliability were determined using data collected by raters who observed and independently rated 22 community and home activity settings, selected to provide a mix of active vs. passive, outdoor vs. indoor, formal (structured) vs. informal, and group vs. solitary activity settings. The MEQAS rating scale ranges from 1 (not at all) to 7 (to a very great extent) and an aggregate score is calculated for pairs of raters.

The 32-item MEQAS has six scales with very good to excellent internal consistency reliability (Cronbach's alphas from 0.76 to 0.96 ): Opportunities for Social Activities, Opportunities for Physical Activities, Pleasant Physical Environment, Opportunities for Choice, Opportunities for Personal Growth, and Opportunities to Interact with Adults. Scale inter-rater reliabilities ranged from 0.60 to 0.93 and test-retest reliabilities ranged from 0.70 to 0.90 . Construct validity has been demonstrated by the ability of the MEQAS to differentiate various types of activity settings.

For the feasibility study, two trained raters conducted observations using the MEQAS. We generated mean scores for each of the six scales for each activity setting and used these 
scores to inform the overall analysis of case data.

Subjective Experiences of Activity Settings (SEAS)

As research in the area of participation grows, there is an identified need for measures that do more than specify what children/youth do and with what frequency. In particular, there is a need to better understand subjective aspects of participation, including the notion of meaningful engagement. 'Participation', 'involvement', and 'engagement' are often used synonymously, but there is a need to differentiate these aspects of experience. There is evidence that disabled people themselves conceptualize participation in terms of active and meaningful engagement, social connection, and choice and control [18].

The SEAS [10] was developed to measure key aspects of the experiences of youth with or without physical impairments in recreational and leisure activity settings at home and in the community. Youth are asked to rate their experiences of a particular activity setting on a bipolar 7-point scale ranging from -3 to +3 , with both endpoints labeled (e.g., I was having fun vs. I wasn't having fun; I tried something new vs. I didn't try anything new). Youth are asked to choose one of the statements on either end of the scale that best expresses how they felt while doing the activity. They are then asked to indicate how much they agree with the statement by choosing either 'Agree a Little', 'Agree', or 'Strongly Agree.' If the activity did not make them feel one way or the other, they are asked to select 'Neither' in the middle of the scale (0). A nonapplicable option is also provided.

The 22-item SEAS has five reliable scales (alphas from 0.71 to 0.88 ) capturing: Personal Growth (6 items), Psychological Engagement (4 items), Social Belonging (4 items), Meaningful Interactions (3 items), and Choice and Control ( 4 items). The mean test-retest reliability was 
.68; we expected reliabilities to be moderate due to time 2 differences in the activities taking place and/or people present. Construct validity has been demonstrated by the ability of the SEAS to differentiate various types of activity settings.

For the feasibility study, youth completed the SEAS at the end of two activity settings. SEAS scores were generated for each activity setting and a table was created that provided ratings for the individual item as well as the mean rating for each scale. These ratings scores were then compared with the other data sources in the case analysis (see below).

\section{Children's Assessment of Participation and Enjoyment (CAPE)}

The CAPE is a psychometrically sound and well established, self-report measure of participation in leisure and recreation activities $[41,42]$. Information from the CAPE was used to provide a picture of participants' most frequent activity settings. It was reviewed with participants to facilitate choosing their two activity setting events for data collection.

\section{Qualitative Methods}

Qualitative methods provide the means to explore youths' perspectives of their activity setting experiences and illuminate place-based mediators of activity participation. In keeping with the epistemological approach of the overarching study [19] we utilized a descriptive exploratory approach $[20,21]$. The qualitative methods focused on in-depth exploration of activity experiences that could illuminate the quantitative data [21,22], as well as explore the broader social mediators of activity beyond the delimited activity setting. The methods included photo-elicitation, observations, electronic interviews, and face-to-face interviews. 
Photo-elicitation is the research process by which participant-generated photographs are used to enrich discussions in individual qualitative interviews. These methods have been shown to facilitate rapport between researcher and interviewee, lessen potential awkwardness of interviews by providing a point of focus, and introduce relevant topics potentially unknown to the researcher [23-26]. Photographs can increase children and youths' engagement in research, encourage them to express their ideas, reduce self-consciousness and alter power dynamics [27-30].

Observational methods allow researchers to record the details of activity and interactions that may seem unremarkable to participants and not shared in interviews [31:132]. Observational research can include everything from no engagement with participants to the 'complete participant' who is a part of the group under study [31:133-4, 32]. In our study, interaction with the participants varied depending on the nature of the activity. The observations provided a rich appreciation for the activity setting that could be probed within an interview [32], and afforded the opportunity to ask questions while the participant was immersed in the activity setting.

Electronic interviewing is increasingly used as part of a 'toolbox' of options for investigating participant perspectives [33-35]. In our study, eight to 10 written questions were emailed to participants after the activity and their answers were returned prior to the interview (see Data Collection below). Participants could then respond at their own pace, and it allowed us to probe their answers in greater depth within the interview $[35,36]$.

Semi-structured face-to-face interviews were conducted at a private location of the participant's choosing. The interview guide consisted of generic and specific questions that 
were constructed for each participant. Data collected during the activities (i.e., participant generated images, SEAS responses, email responses and RA observations), were used as points of discussion and prompts. Audio-recorded Interviews were later transcribed verbatim.

Qualitative Analysis: The qualitative data were analyzed using a flexible coding system derived from and consistent with the research objectives and the study's descriptive exploratory framework. Initial deductive codes related to experiences and meanings of activity settings, inclusion/exclusion, participation, interactions and features of activity settings. We also explored the data to deepen interpretations of participant responses on individual SEAS items. Multiple readings by eight team members were used to facilitate the identification of patterns, recurring relationships, and conceptual congruence or incongruence. The multidisciplinary team held two meetings to discuss the main themes and impressions of Hannah's data; and discuss alternate explanations and interpretations.

Physiological Measures

Physiological data were collected to provide episodic descriptions of engagement experiences during an activity. Physiological data provide a language-free measure of engagement, and can therefore add insight into the experiences of youth beyond what is captured verbally or by standardized questionnaires.

Engagement as it is used here is defined as physical, cognitive, and affective/psychological involvement with an activity $[12,37,38]$. There is evidence to suggest that changes in these dimensions of involvement are associated with measureable physiological changes, including those reflecting the activity of the autonomic nervous system (ANS) $[39,40]$. The ANS is part of the nervous system responsible for regulating physiological parameters such 
as blood pressure, heart and breathing rates, perspiration level, and body temperature. In general, activity of the ANS is involuntarily modulated by external stimuli and affective states. When the body encounters a stressful situation, the ANS promotes what is known as the 'fight or flight' response, preparing the body to appropriately respond to the situation.

During Phase One, we investigated the possibility of using ANS signals for detecting activity engagement [12]. We demonstrated that when using changes in cardiac activity, respiration, electrodermal activity, limb acceleration, and skin temperature, two and three different levels of activity engagement can be automatically differentiated from each other with high accuracies ( $81 \%$ and $74 \%$, respectively).

Based on these results, we developed the Heat ECG Acceleration Respiration Transdermal (HEART) measurement system. The HEART employs a set of non-invasive and inexpensive wireless sensors and a custom set of wearable casings (figure 1). This unique design allows us to collect ANS signals in a manner that is relatively robust to involuntary movements, which corrupt the quality of ANS signals.

For the study, the time course of the signals was mapped onto participants' activities to compare physiological change corresponding to activities of greater or lesser engagement (e.g. Figure 3).

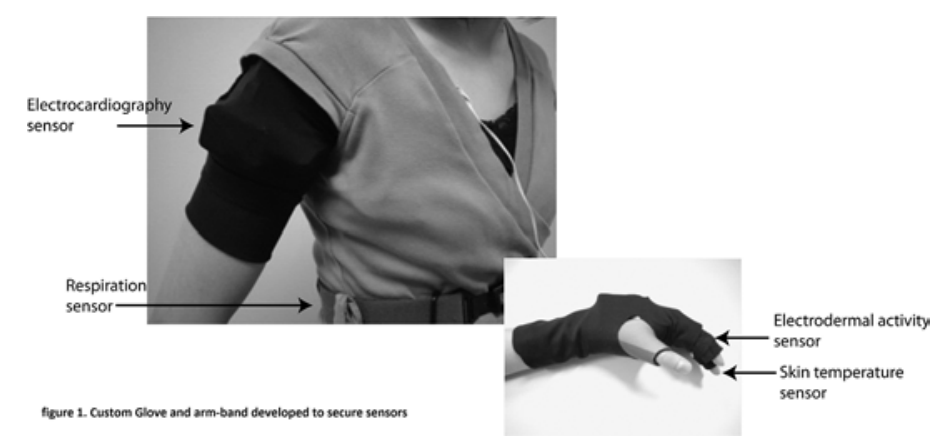




\section{Data Collection}

Data were collected with Hannah over four 'visits': planning and consent (Visit 1), two activity setting visits (Visit 2 and 3), and a qualitative interview (Visit 4). Visits 1, 3, and 4are described below, including how the methods were integrated to generate diverse forms of data. For purposes of illustration, only one activity setting visit, Shopping at the Sports Store (Visit 3) is described.

\section{Visit 1: Planning and Consent}

This visit had four purposes: explain the study and seek consent, administer the CAPE, identify activities for data collection, and adapt the camera set-up according to the participant's abilities. The CAPE provided information on the scope of participants' activities and was used to facilitate a conversation with participants in order to collaboratively choose the two activity settings for the research. For Hannah, 'Visit 1' actually required three meetings to complete all of the tasks within her time constraints.

\section{Visit 3: Activity Setting, Shopping at the Sports Store}

The setting was a sporting apparel store located in a suburban strip mall. Three RAs accompanied Hannah. RA1 was primarily responsible for collecting the physiological data and the SEAS, RA2 was primarily responsible for qualitative observations, and RA3 was being trained for the study. At least two RAs were needed for logistical purposes as a significant amount of equipment needed to be set up, monitored and transported on foot during the activity. This included the HEART unit, sensors and their casings, a laptop, and camera mounts. Both RAs 
completed the MEQAS at the end of the activity setting experience.

At Hannah's suggestion, set up took place at an indoor mall across the street from the sports store. This location had a space outside the restrooms that provided relative privacy for affixing the chest wall sensors. It took about an hour to outfit Hannah with the HEART device and camera equipment and record the five minute HEART baseline measurement. Hannah was reminded to take as many photos or video clips of the activity and setting as she liked. At Visit 1, we provided a list of suggestions for the photographs (Box 1 ) but emphasized again that anything was acceptable.

\section{Box 1. Photo and Video Instructions for Participants}

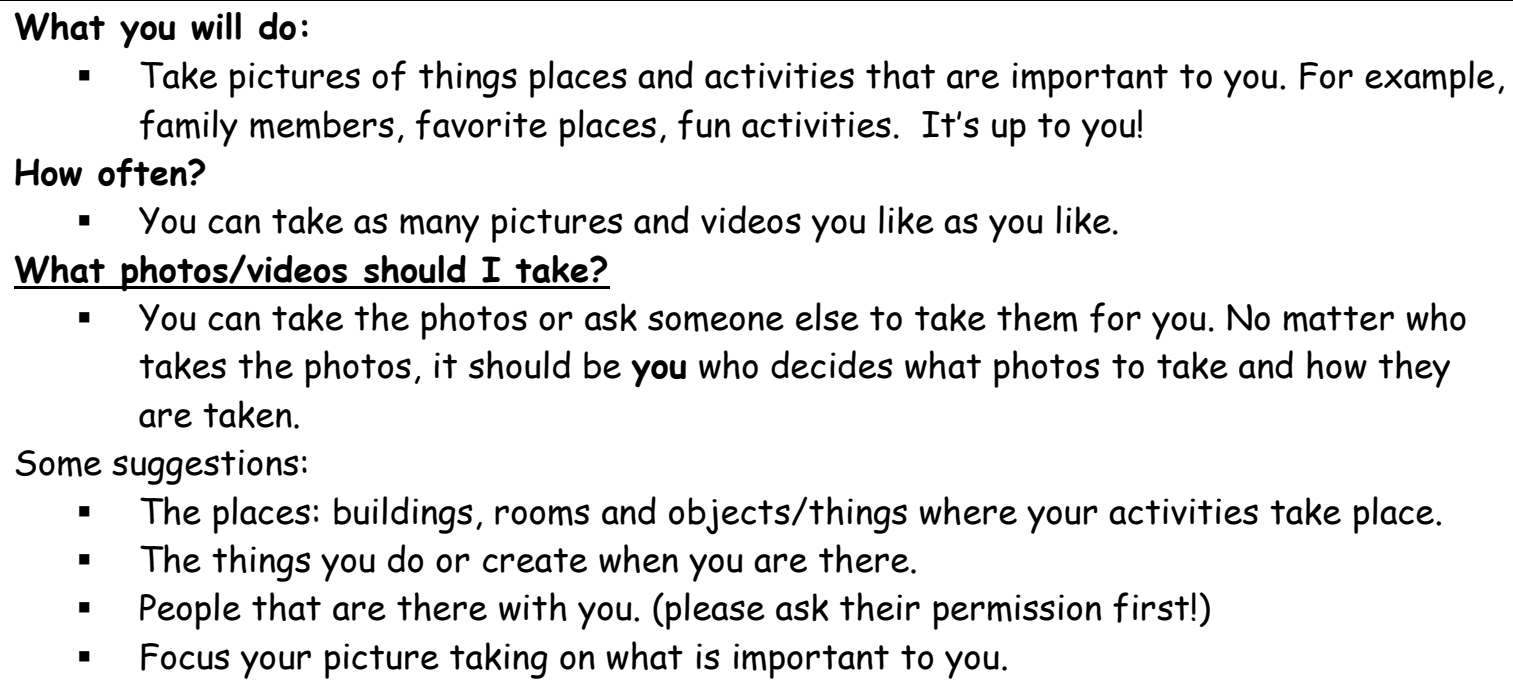

- Take pictures of things places and activities that are important to you. For example, family members, favorite places, fun activities. It's up to you!

- You can take the photos or ask someone else to take them for you. No matter who takes the photos, it should be you who decides what photos to take and how they are taken.

Some suggestions:

- The places: buildings, rooms and objects/things where your activities take place.

- The things you do or create when you are there.

- People that are there with you. (please ask their permission first!)

- Focus your picture taking on what is important to you.

The group left the mall to proceed across a major intersection to the sports store. This took approximately 15 minutes and involved crossing two large parking lots and a very busy, six-lane intersection. As part of the qualitative data collection, RA2 and Hannah talked as they walked to the store. They discussed, amongst other things, Hannah's community mobility challenges of which these were typical. 
The HEART, SEAS and MEQAS data required defined start and end points of data collection within a delimited activity setting. Thus, while the qualitative data collection commenced as soon the RAs met with Hannah, shopping at the sports store was the designated activity setting for the HEART, SEAS and MEQAS.

Observations: Hannah had trouble entering the store because a large lip on the door frame that made wheelchair access difficult. Once inside, she approached a female staff person and initiated a conversation. The staff person seemed to know Hannah from previous visits and they exchanged a few friendly words. When asked about their familiarity, Hannah replied, ‘ don't come that often. I'm just social!' Hannah's wheelchair barely fit through the store aisles but she was able to navigate without assistance - although she remarked that she had "knocked things over' there in the past. She looked at several pairs of athletic shoes and clothing with the salesperson's assistance. They continued to have friendly conversation, frequently laughing and discussing past encounters. Towards the end of the activity, Hannah's phone rang and she briefly chatted with her friend. As she prepared to leave the store, Hannah thanked the salesperson and said goodbye. As she moved towards the door, a man standing near the door said 'heads-up' to another young man who was standing closer to the exit. There was a large box that was not blocking Hannah's path, but the men moved it further away from her path. Hannah thanked them as she and the RAs left the store.

The shopping activity lasted 30 minutes. At its completion, another 5 minute HEART resting measurement was taken, and then the team returned to the mall across the street. Once there, the RAs administered the SEAS and completed the MEQAS. The entire data collection period was approximately 2 hours. 
Visit 4: Electronic Questions and Qualitative Interview

Nine email questions were prepared for Hannah that were either generic (e.g., what would have made this activity perfect?), specific to the activity setting (e.g., what were the good things about the store itself? Probes: the space, people in it, the merchandise) or related to her SEAS responses (e.g., in your responses you indicated you felt a little unsafe when doing this activity. What made you feel a little unsafe?). Hannah requested that she reply to the email questions over the phone because typing was onerous. Since this was difficult to schedule, the questions were incorporated into the beginning of the interview.

RA2 conducted the interview at the rehabilitation centre at Hannah's request. The semistructured interview guide included questions regarding both of Hannah's observed activity settings. For the 'shopping at the sports store' activity setting, Hannah had taken 81 photos and nine videos. During the activity she spoke mostly about physical accessibility and safety (eg 'I know the mall has good accessibility features', and, 'Whenever I go out, the first thing on my mind is am I gonna to go to a place where I have a bathroom to go to?') The RA chose two video clips that illustrated these topics for discussion during the interview. The first clip showed how Hannah was rather violently jostled as she manoeuvred over the large lip on the doorway (figure 2). The second clip was taken outside as Hannah returned to the mall. The clip shows the road ahead of Hannah as she navigates her wheelchair in the face of oncoming traffic because of lack of sidewalks. The interview was 105 minutes in duration. 




figure 2. Entrance to Sports Store

\section{Results}

Below we describe key results in order to illustrate how the different types of data informed each other in the analysis, and how they can be presented to provide a multifaceted picture of activity setting experiences.

MEQAS

The two RAs were similar in their ratings of the sports store setting (table 1). Looking at the mean scores, it can be seen that the activity setting was rated most highly in terms of Opportunities for Choice ( $M=6.83$, where 7 means 'to a very great extent'), followed by Opportunities to Interact with Adults $(M=5.84)$, and then Opportunities for Social Activities $(M=$ 4.33). Both observers rated the activity setting as particularly low in Opportunities for Physical 
Activities $(M=2.08$, where 2 means 'to a very small extent') and Opportunities for Personal

Growth $(M=3.10$, where 3 means 'to a small extent'). Opportunities for Personal Growth refers to opportunities to choose from a variety of different activities to engage in, multiple opportunities for personal growth and social experience, and opportunity for identity development. The RAs also assigned low ratings to Pleasant Physical Environment $(M=2.42)$.

Table 1. Mean MEQAS Scale Scores*

\begin{tabular}{lcccccc}
\hline & $\begin{array}{c}\text { Opportunities } \\
\text { for Social } \\
\text { Activities }\end{array}$ & $\begin{array}{c}\text { Opportunities } \\
\text { for Physical } \\
\text { Activities }\end{array}$ & $\begin{array}{c}\text { Pleasant } \\
\text { Physical } \\
\text { Environment }\end{array}$ & $\begin{array}{c}\text { Opportunities } \\
\text { for Choice }\end{array}$ & $\begin{array}{c}\text { Opportunities } \\
\text { for Personal } \\
\text { Growth }\end{array}$ & $\begin{array}{c}\text { Opportunities } \\
\text { to Interact } \\
\text { with Adults }\end{array}$ \\
\hline Rater 1 & 4.78 & 2.00 & 2.50 & 7.00 & 2.80 & 6.67 \\
Rater 2 & 3.89 & 2.17 & 2.33 & 6.67 & 3.40 & 5.00 \\
$\begin{array}{l}\text { Mean } \\
\text { Rating }\end{array}$ & 4.33 & 2.08 & 2.42 & 6.83 & 3.10 & 5.84 \\
$\begin{array}{l}\text { St Dev. } \\
\text { (of the } \\
\text { means) }\end{array}$ & 0.63 & 0.12 & 0.12 & 0.24 & 0.42 & 1.18 \\
\hline
\end{tabular}

* $1=$ not at all, $2=$ to a very small extent, $3=$ to a small extent, $4=$ to a moderate extent, $5=$ to a fairly great extent, $6=$ to a great extent, $7=$ to a very great extent

SEAS

Table 2 provides Hannah's SEAS ratings of the activity setting. The scale scores indicate that Hannah agreed that the activity setting provided a feeling of Meaningful Experience $(M=$ 2.25 or agree), Choice and Control $(M=2.00)$, and Social Experience $(M=1.75)$, and her ratings also indicated agreement with experiencing Psychological Engagement ( $M=1.50$ or agree a little). She did not experience a sense of Personal Growth ( $M=-1.67$ or disagree). 
Hannah's responses to the SEAS items provide additional information for understanding her experience (table 2). Focusing on the items she rated most highly (3s or Strongly Agree), her ratings indicated she got along with others (Social Belonging), talked about her thoughts and feelings, shared ideas about things that were important to her, and had good conversations with others (Meaningful Interactions). She also felt she was in control, could choose what to do, and had a say in things (Choice and Control). These ratings resonate with the qualitative results discussed below.

Table 2. SEAS Item Scores by Scale*

\begin{tabular}{|c|c|c|c|}
\hline $\begin{array}{l}\text { SEAS Scales (Total } \\
\text { Number of Items) }\end{array}$ & $\begin{array}{l}\text { Mean and } \\
\text { Median }\end{array}$ & Item & $\begin{array}{c}\text { Hannah's Ratings } \\
\text { (Descending } \\
\text { within scales) }\end{array}$ \\
\hline \multirow{6}{*}{$\begin{array}{l}\text { Personal Growth } \\
\text { (6) }\end{array}$} & \multirow{6}{*}{$\begin{array}{c}\text { Mean }= \\
-1.67 \\
\text { Median= }-3\end{array}$} & I discovered things about myself & 1 \\
\hline & & I grew or changed & 0 \\
\hline & & I was challenged & -2 \\
\hline & & I learned a new skill & -3 \\
\hline & & I became better at something & -3 \\
\hline & & I tried something new & -3 \\
\hline \multirow{4}{*}{$\begin{array}{l}\text { Psychological } \\
\text { Engagement } \\
\text { (4) }\end{array}$} & \multirow{4}{*}{$\begin{array}{c}\text { Mean= } \\
1.50 \\
\text { Median=2 }\end{array}$} & I was having fun & 2 \\
\hline & & (I felt in) a good mood & 2 \\
\hline & & I was interested & 2 \\
\hline & & (I felt) excited & 0 \\
\hline \multirow{4}{*}{$\begin{array}{l}\text { Social Belonging } \\
\text { (4) }\end{array}$} & \multirow{4}{*}{$\begin{array}{c}\text { Mean }= \\
1.75 \\
\text { Median= 2 }\end{array}$} & I got along with others & 3 \\
\hline & & I was supported and encouraged by others & 2 \\
\hline & & I was valued by others & 2 \\
\hline & & I belonged (i.e. I was part of the group) & 0 \\
\hline \multirow{4}{*}{$\begin{array}{l}\text { Meaningful } \\
\text { Interactions } \\
\text { (4) }\end{array}$} & \multirow{4}{*}{$\begin{array}{c}\text { Mean }= \\
2.25 \\
\text { Median= } 3\end{array}$} & I talked about my thoughts and feelings & 3 \\
\hline & & I shared ideas about things important to me & 3 \\
\hline & & I had good conversations with others & 3 \\
\hline & & I shared something special & 0 \\
\hline \multirow{5}{*}{$\begin{array}{l}\text { Choice and } \\
\text { Control } \\
\text { (4) }\end{array}$} & \multirow{5}{*}{$\begin{array}{c}\text { Mean }= \\
2.00 \\
\text { Median= } 3\end{array}$} & I could choose what to do for the most part & 3 \\
\hline & & I was in control (i.e. made good decisions, in & \\
\hline & & charge) & 3 \\
\hline & & I had a say in things & 3 \\
\hline & & I was free of pressure & -1 \\
\hline
\end{tabular}

\footnotetext{
$*+3=$ Strongly Agree, $+2=$ Agree,$+1=$ Agree a Little, $0=$ Neither, $-1=$ Disagree a Little, $-2=$ Disagree, $-3=$ Strongly Disagree
} 
Broadly speaking, increases in heart rate are associated with psychological arousal (e.g., due to anxiety or excitement). Figure 3 suggests that Hannah's heart rate increased when interacting on the phone and when interacting with the salesperson, suggesting that her activities involving social interaction resulted in higher arousal.

The questionnaire and qualitative data provide context for these physiological observations. The MEQAS data shows relatively high ratings for the activity setting with respect to opportunities for social activities and interaction with adults. Furthermore, the SEAS results indicate that Hannah felt that she had a positive social experience (in particular 'got along with others' and 'had good conversations'). This is discussed further in the qualitative results. Collectively, these findings suggest that, in this activity, the increased heart rate observed was associated with positive arousal.

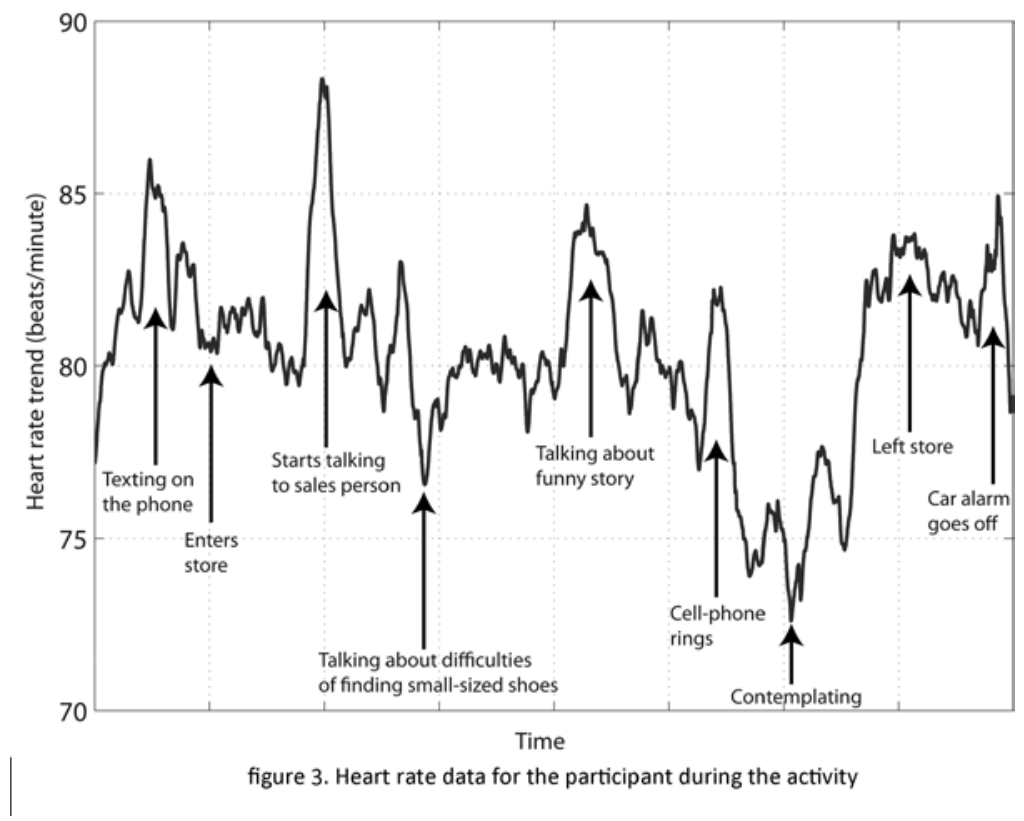

Qualitative Results 
Qualitative analysis of Hanna's data provided insight into her particular experiences that informed data collection with future participants and contextualized the other findings. The most prominent finding emerging from the analysis was a 'process of trade-offs' whereby Hannah would carefully consider a number of factors in determining whether or not an activity was worth pursuing on a given day:

I can walk but is it worth it? Am I going to enjoy the activity?

During the shopping activity and within her interview, Hannah generally focused on the material mediators that facilitated or impeded her ability to participate in shopping and other activities. These included: weather, physical accessibility, availability of human assistance, and the planning/resources needed. The mediators were interrelated: for example, planning included the time and effort to investigate the accessibility features of an activity setting.

And I also just think about the logistics... What if the subway breaks? What if the bus never comes? Like, I always have to think about Plan B, so do I have money on me? Is my cell phone charged, is it working?... And I always call, you have to call if I want to take the subway. I have to call the customer service line making sure that the stops which I want on the subway, like, are working.

Time, effort, and fatigue were key issues in Hannah's assessment of tradeoffs and the worth of an activity. Hannah stated that she wheeled or used public transport for the majority of activities and thus needed to ensure her wheelchair batteries were charged and her chair was in good repair:

I think about, is that safe, and how can I be safe? Like ooh, I'm going to be crossing like Dundas or Yonge and University. Hmm. is that safe? So first of all, what time do I have to get there? I need to give myself two hours, and if it's rush hour and - I always like to double check my chair. I call the technician up "Hey, I have loose screws. Can you come and tighten them?" [Laughs] 
Physical accessibility included barriers to getting to the activity setting: navigating curb cuts, 'ice curbs' created by snow removal, and lack of sidewalks in parking lots. This was demonstrated in entering the shopping activity setting where Hannah encountered accessibility challenges in relation to the width of store doors and aisles, the height of product displays, and a difficult-to-access entrance way.

Hannah had previously visited the sports store and knew she could get through the front door, though with some difficulty. When asked what would have made this activity setting a better experience for her, she immediately referred to changing the doorway to improve accessibility. Issues regarding accessibility were woven throughout Hannah's account. She noted that she pre-screens retail stores to determine their accessibility:

I actually went by it a couple times, just like, almost purposefully just to see how the store is, if it's wide enough, like, I didn't actually go in, but I can tell from the outside if it's wide-enough or not.

The qualitative analyses illuminated the SEAS and HEART results by confirming that Hannah's positive relationship with the salesperson was an important factor in determining her interest and willingness in returning to the store, enjoyment of the activity, and feeling that it was worth the effort. Her positive portrayal of her relationship with the salesperson suggests that the arousal data from the HEART indicate a positive psychological state.

The availability of human assistance in a welcoming environment was a key mediator in Hannah's choice of the activity setting and helped explain her positive scores on the SEAS scales of Social Belonging and Meaningful Experience. Hannah revealed that part of planning an independent shopping activity included coordinating her visit with the scheduled work days of 
helpful staff. She noted that she found the store staff particularly helpful, 'even the guys', which was not always the case in other retail stores.

In order for people to interact with you, you need to interact with people. You can hit the ball into their court - whether they hit it back nicely, or hit it back really poorly, it's up to them.

The analysis also helped explain her positive scores on the Choice and Control scale. Hannah indicated that she was in a familiar environment where she could get the assistance she needed to carry out the tasks associated with navigating the store, examining and trying on shoes and clothing, and purchasing something if she wished.

Thus Hannah's choices and possibilities of activity were circumscribed by a number of considerations, some of which involved semi-permanent features of places and others that could change from day-to-day. The planning involved, particularly in unknown settings, could sometimes outweigh the potential value of the activity. Hannah's discussion of the sport store activity setting suggested it largely promoted a sense of ease, comfort, and familiarity. The setting was welcoming because the salesperson was congenial, helpful and unhurried. Hannah largely had control over what she wanted to do and how to do it. The store was close to home and relatively easy for Hannah to access, despite having to drive her wheelchair on the same surface as the cars across two large parking lots, and having to negotiate a curb and a large lip to get into the store doorway.

\section{Discussion: Lessons Learned}

The feasibility study provided the opportunity to field test the viability of simultaneously combining a number of diverse data collection methods. We learned practical lessons 
concerning the joint use of the three methods, lessons specific to a given method, and lessons concerning next steps for integrating the data.

\section{Practical Lessons}

One of the first lessons we learned was the intensive amount of time, planning and personnel hours required to coordinate the logistics of data collection. Coordinating four visits with the two RAs and participants (and sometimes parents) was challenging and often resulted in longer data collection periods. For example, Hannah's 'Visit 1' had to be spread over the course of three visits over two weeks.

The primary challenge was determining how to collect concurrent data with the least amount of cross-interference between methods. This required compromises and ingenuity. For the qualitative data we wanted the activity to be as 'natural' as possible with minimal imposition of the research and researchers on the activity settings. Our inclination would either have been to exclude the RAs from the activity, or to have a single participant observer. However the requirements of collecting the SEAS, MEQAS and physiological data required the presence of at least two RAs. Instead of viewing this as a weakness, we capitalized on the required presence of the RAs to incorporate a component of qualitative participantobservation. This allowed for a richer exploration of the activity setting experiences in the interviews because the RA had been immersed in the setting. It also helped to establish a stronger rapport. The RAs thus had multiple roles to fulfill at different times in the data collection period. 
We determined that it was important for each RA to have a basic familiarity with all methods, even when not specifically required to administer them. The RAs could then assist each other with securing the physiological sensors, or recording observations. Having a basic familiarity with all the methods helped sensitize the RAs to how their actions during data collection could potentially influence other methods.

The combined use of the methods extended the length of data collection for each activity setting event. Apart from the activity itself, extra time was needed to attach and remove sensors and collect baseline data, and to administer the SEAS and MEQAS post activity. Although the RAs became more proficient and faster in combining the procedures, there was a risk that participants would become fatigued. This was addressed in part by limiting the length of activities and checking in with participants throughout. Of note, in the larger study (forthcoming) of 20 participants that we have recently completed, youth participants reported that time commitment was not a significant issue. They were excited to be the centre of a research project about their lives and experiences, and to share their achievements and frustrations. Many participants had not previously had the technology to take independent photographs, thus they particularly enjoyed using the adapted cameras to share their stories. Method-Specific Lessons

We also learned that the variability in participants' individual circumstances, preferences, activity setting choices, and abilities required us to build flexibility into our qualitative approach. Thus, while we included observational and interview components with each participant, the amount of interaction in the observations varied. We also learned that electronic questions may be helpful for some participants (primarily AAC users) or, as was the 
case with Hannah, may be less useful or burdensome. We view this flexible approach as a methodological strength, as it employs a variety of tools to explore participants' experiences and generate high quality data to address the research questions $[43,44]$.

We also encountered specific challenges related to collecting the physiological data in the field. This was the first time this type of data was collected outside of a controlled lab setting for the target population. We were unable to collect useable physiological data from our other participant because of difficulties with sensor attachment due to the participant's increased muscle tone and dyskinetic movements. Having a multidisciplinary team was useful in addressing this challenge. The occupational therapists, in consultation with the engineers, devised soft splints and slip-resistant straps for more secure sensor attachments. We conducted additional research to demonstrate that alternate placement sites for sensors (e.g., foot) could be used when hand placement was not possible due to tonal influences or activity demands (e.g., bimanual activities) [45].

Physiological data were initially collected off-line on a wireless device called the 'Shimmer', but without any visual representation of the data, it was difficult for the RAs to determine when technological breakdowns were occurring. To address this, the team engineers developed a computer program for live streaming of data in the field to verify that the signals were recording correctly. We also implemented phone-based engineering support for the RAs to access when they were experiencing technical difficulties.

Data Integration Lessons 
Although the primary aim of the feasibility study was to test the combined use of the methods in the field, we also learned important lessons to facilitate the development of data analysis integration procedures for the full study. We have since developed an approach that draws on a 'follow the thread' technique [46] which we describe in more detail in a forthcoming paper. This involves initial case-by-case comparisons of SEAS items and qualitative data in an iterative interpretative circle that confirms or identifies inconsistencies in findings and develops explanations. In following a thread, data are initially analyzed separately following qualitative and quantitative lines of inquiry, and the overarching themes and questions that emerge are then incorporated into a secondary analysis to look at how the data interact. Through this process we identified emerging interpretive 'threads' or concepts to further interrogate across the data set. Following these threads allowed us to answer questions regarding experiences of social connections, control and choice of activities and setting, social inclusion, and the nature of positive activity experiences.

Work is also underway to develop statistical methods to compare SEAS, MEQAS and physiological data. In particular, we are developing techniques based on canonical correlation and multiple correspondence analyses to correlate aggregate measures of change in physiological signals (e.g., average heart rate change) with SEAS/MEQAS data across participants.

\section{Conclusion}

This feasibility study demonstrated that standardized questionnaires, physiological measures, and qualitative methods can be practically combined to study the activity setting 
participation experiences of disabled youth. The importance of conducting feasibility work was demonstrated in that practical challenges were identified and solved, allowing us to fine tune our procedures for the full study. In addition, the experience assisted us in developing joint data integration and interpretation approaches. Such combined methodologies hold great promise for investigations of the participation experiences of disabled youth in future research. The data are rich and complex but provide a much fuller picture of activity setting experiences than any one method used alone.

Research investigating the real world experiences of children and youth with complex disabling conditions is relatively sparse, and parents have traditionally acted as proxies for their perspectives. In this feasibility study we sought to engage youth directly, and in the field, in order to gather rich and multifaceted data that reflected their real world engagement in activity settings. The study demonstrated the possibility of combining diverse methods to capture experience. We recognize however that the combination of these three approaches is time and resource intensive and may not always be practical. Our combination of the methods in the feasibility study helped with the development of each, and we envision that the methods can be used as stand-alone measures and/or in different combinations with these or other measures across diverse populations of disabled youth. As with any research, the study questions and the depth and breadth of data needed to address the questions adequately will steer how the methods are used and combined in future research. 


\section{Acknowledgements}

We would like to thank the study participants, Freda Goh and Madhu Pinto for their assistance.

\section{Declaration of Interest Statement}

This study was funded by a Canadian Institutes of Health Research Emerging Team Grant (TWC95045). Barbara Gibson was supported by a Canadian Child Health Clinician Scientist Program Career Development Award. 


\section{References}

[1] Morris, J. Impairment and disability: Constructing an ethics of care that promotes human rights. Hypatia 2001; 16(4): 1-13.

[2] James A, Jenks C, Prout A. Theorising childhood. Cambridge: Polity Press \& Blackwell Publishers; 1998.

[3] Christensen P, James A. Research with children: Perspectives and practices. London, England: Falmer Press; 2000.

[4] Barker J, Weller S. Is it fun? Developing children centered research methods. International Journal of Sociology and Social Policy. 2003;23(1/2):33-58.

[5] King, G., Ribgy, P., \& Batorowicz, B. Conceptualizing participation in context for children and youth with disabilites: An activity setting perspective 2013. Disability and Rehabilitation. doi: 10.3109/09638288.2012.748836.

[6] Gallimore, R., Goldenberg, C. N., \& Weisner, T. S. The social construction and subjective reality of activity settings: Implications for community psychology. American Journal of Community Psychology 1993; 21(4): 537-560.

[7] Heft, H., \& Chawla, L. (2006) Children as agents in sustainable development: The ecology of competence. In: C. Spencer \& M. Blades, editors. Children and their environments: Learning, using and designing spaces. Cambridge, UK: Cambridge University Press; 2006. p 199-216.

[8] Spencer, C., \& Blades, M. (Eds.). Children and their environments: Learning, using and designing spaces. Cambridge, UK: Cambridge University Press; 2006.

[9] King, G., Batorowicz, B., Rigby, P., Pinto, M., Thompson L., \& Goh, F. The leisure activity settings and experiences of youth with severe disabilities. Developmental Neurorehabilitation 2013. Early Online, 1-11. doi: 10.3109/17518423.2013.799244.

[10] King, G., Batorowicz, B., Rigby, P., McMain-Klein, M., Thompson, L., \& Pinto, M. (in press). Development of a measure to assess youth self-reported experiences of activity settings (SEAS). International Journal of Disability, Development and Education.

[11] King, G., Rigby, P., Batorowicz, B., McMain-Klein, M., Thompson, L., \& Petrenchik, T. (2012). A direct observation measure of environmental qualities of activity settings (MEQAS). Developmental Medicine and Child Neurology Abstracts, 54(Suppl. 6), 30.

[12] Kushki, A., Andrews, A.J., Power, S.D., King, G., \& Chau, T. Classification of Activity Engagement in Individuals with Severe Physical Disabilities Using Signals of the Peripheral Nervous System. PloS One 2012; 7(2): e30373. 
[13] Noreau, L., \& Boschen, K. (2010) Intersection of participation and environmental factors: A complex interactive process. Archives of Physical Medicine and Rehabilitation 2010; 91(9): S44S53.

[14] Chawla, L. Toward better cities for children and youth. In: L Chawla, editor. Growing up in an urbanising world. London: Earthscan; 2002.

[15] Clark, C., \& Uzzell, D. L. The affordances of the home, neighborhood, school and town centre for adolescents. Journal of Educational Psychology 2002; 22: 95-108.

[16] Horelli, L. Environmental human-friendliness as a contextual determinant for quality of life. Revue europeenne de psychologie appliquee 2006; 56(1): 15-22.

[17] Petrenchik, T. M., \& King, G. A. (2011) Pathways to positive development: Childhood participation in everyday places and activities. In: S. Bazyk, editor. Mental health promotion, prevention, and intervention in children and youth: A guiding framework for occupational therapy. Bethesda, MD: The American Occupational Therapy Association; 2011. p 71-94.

[18] Hammel, J., Magasi, S., Heinemann, A., Whiteneck, G., Bogner, J., \& Rodriguez, E. (2008) What does participation mean? An insider perspective from people with disabilities. Disability and Rehabilitation 2008; 30(19): 1445-1460.

[19] Crotty M. The Foundations of Social Research: Meaning and Perspective in the Research Process. London: Sage Publications Ltd.; 1998.

[20] Sandelowski M. What's in a name? qualitative description revisited. Research in Nursing \& Health. 2010;33:77-84.

[21] Sandelowski M. Whatever happened to qualitative description? Res Nurs Health. 2000 August;23(4):334-40.

[22] Hanson WWE. Mixed methods research designs in counseling psychology. Journal of counseling psychology. 2005;52(2):224-35.

[23] Croghan R, Griffin C, Hunter J, Phoenix A. (Young people's constructions of self: Notes on the use and analysis of the photo-elicitation methods. International Journal of Social Research Methodology 2008; 11(4): 345.

[24] Strack RW, Magill C, McDonagh K. Engaging youth through photovoice. Health Promotion Practice 2004; 5(1): 49-58. 
[25] Radley A, Taylor D. Images of recovery: A photo-elicitation study of the hospital wards. Qualitative Health Research 2003; 13(1): 77-99.

[26] Killion CM, Wang CC. Linking African American mothers across life stage and station through photovoice. Journal of Health Care for the Poor and Underserved 2000; 11(3): 310325.

[27] Adams, A., Theodore, D., Goldenberg, E., McLaren, C., \& McKeever, P. Kids in the atrium: Comparing architectural intentions and children's experiences in a pediatric hospital lobby. Social Science \& Medicine 2010; 70(5): 658-667.

[28] Capello, M. Photo interviews: Eliciting data through conversations with children. Field methods 2005; 17(2): 170-182.

[29] Einarsdottir, J. Playschool in pictures: Children's photographs as a research method. Early Child Development and Care 2005; 175(6): 523-541.

[30] Clark-Ibanez M. Framing the social world with photo-elicitation interviews. American Behavioral Scientist 2004; 47(2): 1507-1527.

[31] Green, J., \& Thorogood, N. Qualitative methods for health research. Los Angeles, CA: Sage; 2004.

[32] Bogdewic, S. P. Participant observation. In: B. F. Crabtree, \& W. L. Miller, editors. Doing qualitative research. Thousand Oaks, CA: Sage Publications, Inc; 1999. p 47-69.

[33] Bjerke, T. N. When my eyes bring pain to my soul, and vice versa: Facing preconceptions in email and face-to-face interviews. Qualitative Health Research 2010; 20(12): 1717-1724.

[34] Ison, N. L. Having their say: Email interviews for research data collection with people who have verbal communication impairment. International Journal of Social Research Methodology 2009; 12(2): 161-172.

[35] Opdenakker, R. 2006. Advantages and disadvantages of four interview techniques in qualitative research. [Electronic version]. Forum: Qualitative Social Research, 7(4) Art. 11, http://nbn-resolving.de/urn:nbn:de:0114-fqs0604118.

[36] Egan, J., Chenoweth, L., \& McAuliffe, D. Email-facilitated qualitative interviews with traumatic brain injury survivors: A new and accessible method. Brain Injury 2006; 20(12): 12831294.

[37] Fredricks, J. A., Blumenfeld, P. C., \& Paris, A. H School engagement: Potential of the concept, state of the evidence. Review of Educational Research 2004; 74(1): 59-109. 
[38] Jimerson, S. R., Campos, E., \& Greif, J. L. Toward an understanding of definitions and measures of school engagement and related terms. The California School Psychologist 2003; 8(1): 7-27.

[39] Kreibig, S.D., Wilhelm, F.H., Roth, W.T., \& Gross, J.J. Cardiovascular, electrodermal, and respiratory response patterns to fear-and sadness-inducing films, Psychophysiology 2007; 44(5): 787-806.

[40] Ekman, P., Levenson, R.W., \& Friesen, W.V. Autonomic nervous system activity distinguishes among emotions. Science 1983; 221(4616): 1208-1210.

[41] King, G. A., Law, M., King, S., Hurley, P., Hanna, S., Kertoy, M. Rosenbaum, P., \& Young, N. Measuring children's participation in recreation and leisure activities: construct validation of the CAPE and PAC. Child: Care, Health and Development 2006; 33(1): 28-39.

[42] King, G., Law, M., King, S., Hurley, P., Rosenbaum, P., Hanna, S., Kertoy M., \& Rosenbaum, P. Children's Assessment of Participation and Enjoyment (CAPE) and Preferences for Activities of Children (PAC). San Antonio, TX: Harcourt Assessment; 2004.

[43] Darbyshire, P., MacDougall, C., \& Schiller, W. Multiple methods in qualitative research with children: More insight or just more? Qualitative Research 2005; 5(4): 417-436.

[44] Latham, A. Research, performance, and doing human geography: Some reflections on the diary-photograph, diary-interview method. Environment and Planning.A 2003; 35(11): 19932017.

[45] Kushki, A., Fairley, J., Merja, S., King, G., \& Chau, T. Comparison of blood volume pulse and skin conductance responses to mental and affective stimuli at different anatomical sites. Physiological Measurement 2011; 32(10): 1529-1539

[46] O'Cathain, A., Murphy, E., \& Nicholl, J. Three techniques for integrating data in mixed methods studies. British Medical Journal 2010; 341: 1147-1150. 